\title{
Why the processing of repeated targets are better than that of no repetition: evidence from easy-to-difficult and difficult-to-easy switching situations
}

\author{
Guangheng Dong ${ }^{1 *}$, Hongli Zhou' ${ }^{1}$ Xiao Lin ${ }^{1}$, Yanbo $\mathrm{Hu}^{2}$ and Qilin Lu ${ }^{3}$
}

\begin{abstract}
Background: Previous studies have found that the processing of repeated targets are easier than that of non-repetition. Although several theories attempt to explain this issue, the underlying mechanism still remains uncovered. In this study, we tried to address this issue by exploring the underlying brain responses during this process.

Methods: Brain activities were recorded while thirty participants performing a Stroop task (Chinese version) in the MRI scanner. Using pseudo-random strategies, we created two types of switching conditions (easy-to-difficult; difficult-to-easy) and relevant repeating conditions.

Results: The results show that, in difficult-to-easy switching situation, higher brain activations are found in left precuneus than repeating ones (the precuneus is thought related with attention demands). In easy-to-difficult switching conditions, higher brain activations are found in precuneus, superior temporal gyrus, posterior cingulate cortex, and inferior frontal gyrus than repeating trials (most of these regions are thought related with executive function). No overlapping brain regions are observed in con_CON and incon_INCON conditions. Beta figures of the survived clusters in different conditions, correlations between brain activations and switch cost were calculated.

Conclusions: The present study suggests that the feature that response time in switching trials are longer than that in repeating trials are caused by the extra endeavors engaged in the switching processes.
\end{abstract}

Keywords: Switch cost, Priming effect, Switching situation, Repeating situation

\section{Introduction}

Plenty of studies have found that the current trial performance is influenced by previous one [1-5], and that the processing of repeated targets are better than that of non-repeated ones [6-8]. For example, individuals tend to show shorter response time and higher response accuracy to incongruent trials following incongruent trials (incon_INCON) compared to incongruent trials following congruent trials (con_INCON) [4,5,9]. In addition, response times for congruent trials following congruent trials (con_CON) tend to be shorter than those for congruent trials followed by incongruent trials (incon_CON) $[10,11]$.

\footnotetext{
* Correspondence: dongguangheng@zjnu.edu.cn

'Department of Psychology, Zhejiang Normal University, 688 Yingbin Road, Jinhua, Zhejiang Province, P.R. China

Full list of author information is available at the end of the article
}

Several theories contributed to understand how previous processed task affect the processing of subsequent stimuli: mental set switching, conflicting adaption, and priming effect. Mental set switching (also termed "mental switch", "mental shifting") has been reported to be involved in nearly any type of cognitive switches [12-14]. It is required when the focus of attention must be altered in order to adapt to a frequently changing environment. It is generally assumed that the act of switching is sub-served by a set of executive control parameters necessary to complete the task [15]. When we switch from one type of task to another, extra executive endeavors should be involved to complete this process. The underlying mechanism behind this is the ability to update the executive control parameters representing a given 'task set' to accommodate a new task set $[15,16]$.

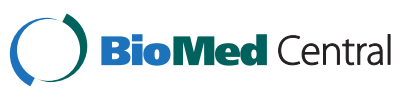


Cognitive adaption refers to the ability to monitor behavior and identify situations that require compensatory adjustments in cognitive resources. Conflicting adaption theory suggests that the conflict triggers the allocation of cognitive resources [5,17]. This theory believe that the phenomenon is due to switching between congruencies and because conflict-driven control reduces the facilitating effect of consecutive repetition of congruent trials [18]. These changes in performance are frequently referred as conflict adaptation or sequential trial effects. According to the conflict monitoring theory, detection of high conflict on incongruent trials should lead to the recruitment of cognitive resources to enhance subsequent performance [19-21]; however, following a congruent trial, less cognitive control is recruited, often resulting in slower RTs and more errors on the subsequent trial.

The priming effect is defined as the influence of an event (prime) on the response of a subsequent event (target), which refers to the exposure to a stimulus influences the response to a later stimulus [6]. The facilitating effect can be observed when there is a link between prime and target. This effect can be independent of the consciousness of priming information, suggesting that the subliminal activation of concepts can effectively influence the judgment and behavior of individuals [22]. The facilitating effect is positive priming, which is thought caused by spreading activation [23-25]. This means that the previous stimulus activates parts of a particular representation or association just before carrying out an action or task. The representation is already partially activated when the second stimulus is encountered, so less additional activation is needed for one to become consciously aware of it.

These three theories focus on different aspects of the cognitive functions during the switching or repeating processes. The set-switching theory pays attention to the extra endeavors in switching trials; The priming emphasizes the facilitation of repeating trials; The conflicting adaption theory believe the conflict control reduces the facilitating effect of consecutive repetition, it focuses on the interaction between facilitating effect and switching cost (extra executive control). Although all of these theories sound reasonable, however, we still don't know which is right or which is better?

In this study, we tried to address this question by exploring the underlying neural activations during this process. Firstly, different brain networks are involved in different theories. Meta-analyses of relevant functional neuroimaging literatures have confirmed the importance of brain activities within the frontal and the parietal cortex regions when a mental set switch is required $[12,26]$. These regions include the executive control related brain regions, such as anterior cingulate cortex [27-30], temporal cortex, and the striatum $[16,31,32]$. However, in priming effect, the middle temporal gyrus and the middle frontal gyrus are typically found engaged in priming processing [33-35]. Thus, we can better understanding the proposed question by comparing activated brain regions during this process.

In addition, task switching theory suggests that people need more endeavors to finish the switching process (switch cost). Thus, the switching trials should engage higher brain activities than repeating trials because they engaged more endeavors in the switching process. However, according to the priming and the facilitation effect, the previous task may triggers network of the following task, which facilitates the processing of current task. Thus, the priming theory and conflict adaption theory predict that a repeated trial would be associated with diminished activations in the same brain regions that were engaged in prior trial. Therefore we can try to distinguish how well different theories explain this issue by comparing the levels of brain activations of different conditions.

\section{Methods}

\section{Participant selection}

All subjects provided written informed consent and thirty subjects $(22.4 \pm 2.8$ years; 5 females $)$ participated. The experiment conforms to The Code of Ethics of the World Medical Association (Declaration of Helsinki). The Human Investigations Committee of Zhejiang Normal University approved this research. All subjects underwent structured psychiatric interviews (M.I.N.I.) [36] performed by an experienced psychiatrist and no active Axis I disorders were present. Depression was further assessed using the Beck Depression Inventory [37] with and exclusionary cut-off of 5 . All subjects are right handed and do not suffered head injury with lost consciousness during their lifetime.

\section{Task and procedure}

An event-related color-word fMRI Stroop task was used in this study. The original version of the Stroop task is in Chinese. Here the English version is to make readers understand this design easily. First, a fixation in the center of the screen $(+)$ lasts for $500 \mathrm{~ms}$. Then, one of the three target color words (e.g. red, green, yellow) was presented in congruent (e.g., the word "RED" in red ink) or incongruent (e.g., the word "RED" in green ink) trials. After $2000 \mathrm{~ms}$, the feedback screen will last for $1000 \mathrm{~ms}$. The task was comprised of 2 sessions of 120 trials each. Each trial was presented for 2000 ms. Participants were asked to press a button to indicate to the ink color of the word as soon as possible using three buttons (i.e., green $=$ thumb, red $=$ index finger, yellow $=$ middle finger; counter-balanced between subjects) of a five-button response box (Invivo Corp.; http://www.invivocorp.com/). 
A black screen was presented for a random interval of 600-1400 ms (average $1000 \mathrm{~ms}$ ) between trials [38] (Figure 1a). The probability of congruent and incongruent trials is $50 \%: 50 \%$. Stimuli were presented and behavioral data were collected using E-prime software (Psychology Software Tools, Inc.). Participants were told that they would be paid a guaranteed 50 Yuan $(\approx 8$ US\$) for participation and, to encourage quick and accurate task performance, were told they would be rewarded with an additional 0-50 Yuan based on their task performance [1/(reaction time * error rate)]. Participants completed an out-of-scanner practice session which continued until they reached an accuracy rate of $90 \%$ or higher.

Although participants were told to perform a totally randomized task, in fact, all trials were predetermined (pseudo-random design). We created four types of conditions with this method: (1) Congruent trial following congruent trial (con_CON); (2) Congruent trial following incongruent trial (incon_CON); (3) Incongruent trial following incongruent trial (incon_INCON); (4) Incongruent trial following congruent trial (con_INCON) (Figure 1b).

There are totally 240 trials in the whole task. Each trial, except the last one, was followed by another trial. In order to create more switching/repeating trials, the number of trials of congruent/incongruent was 120:120, which is a bit different from classical Stroop tasks. Using this method, we created 239 switching trials in four conditions. Thus, each condition consists about 60 trials. In fact, a pseudo-random is not a must because the totally randomized task can also create the same number of switching/repeating trials. However, in order to make the data analysis easier, we used pseudo-random design.

\section{Image acquisition and pre-processing}

Structural images covering the whole brain were collected using a T1-weighted three-dimensional spoiled gradientrecalled sequence $(176$ slices, $\mathrm{TR}=1700 \mathrm{~ms}, \mathrm{TE}=3.93 \mathrm{~ms}$, slice thickness $=1.0 \mathrm{~mm}$, skip $=0 \mathrm{~mm}$, flip angle $=15^{\circ}$, inversion time $1100 \mathrm{~ms}$, field of view $=240^{*} 240 \mathrm{~mm}$, in-plane resolution $=256 * 256$ ). Functional MRI was performed on a $3 \mathrm{~T}$ scanner (Siemens Trio) with a gradient-echo EPI T2 sensitive pulse sequence in 33 slices (interleaved sequence, $3 \mathrm{~mm}$ thickness, TR $=2000 \mathrm{~ms}$, flip angle $90^{\circ}$, field of view $220 \times 220 \mathrm{~mm}^{2}$, matrix $64 \times 64$ ). Stimuli were presented using Invivo synchronous system (Invivo Company, www.invivocorp.com) through a screen in the head coil, enabling participants to view the stimuli.

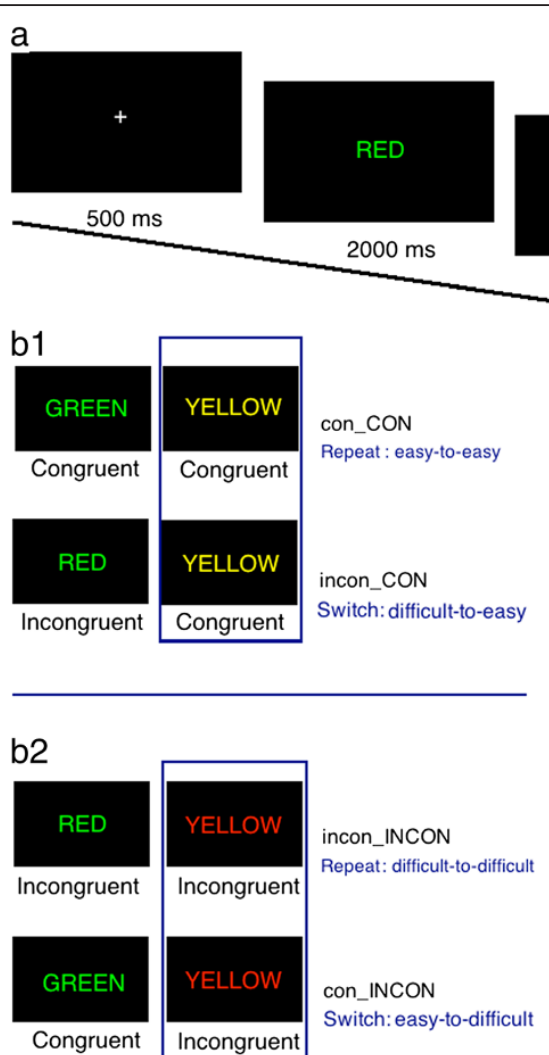

Figure 1 The timeline of one trial and four conditions we created in present study. a, The timeline of one trial in the Stroop task in present study. The original version of the Stroop task is in Chinese. The English description is to make readers understand this design easily. b, Four conditions we created by manipulating the sequence of congruent and incongruent trials in present study. 


\section{First-level regression analysis}

Imaging analysis was conducted using SPM5 (http://www. fil.ion.ucl.ac.uk/spm). Images were slice-timed, reoriented, and realigned to the first volume. T1-co-registered volumes to correct for head movements. Images were then normalized to an MNI space (defined by Montreal Neurological Institute) and spatially smoothed using a 6 mm FWHM Gaussian kernel. A general linear model (GLM) was applied to identify blood oxygen level dependence (BOLD) activation in relation to separate event types. There were four types of trials: incon_CON, incon_INCON, con_INCON, and con_CON. Six headmovement parameters derived from the realignment stage were included to exclude motion related variances. GLM was independently applied to each voxel to identify voxels that were significantly activated for the each event that was modeled. All incorrect answers will be excluded from further analysis.

\section{Second-level analysis}

Second level analysis treated inter-subject variability as a random effect. First, we determined voxels showing a main effect in different conditions relative to implicit baseline. Second, we tested for voxels that showed higher or lower activity in two contrasts of interest (difficult-to-easy: incon_CON > con_CON; easy-to-difficult: con_INCON > incon_INCON). We first identified clusters of contiguously significant voxels at an uncorrected threshold $p<0.01$, as also used for display purposes in the figures. We then tested these clusters for cluster-level FWE correction $p<0.01$ and the AlphaSim estimation indicated that clusters with 30 contiguous voxels would achieve an effective FWE threshold $p<0.01$. The smoothing kernel used during simulating false-positive (noise) maps using AlphaSim was $6.0 \mathrm{~mm}$, and was estimated from the residual fields of the contrast maps being entered into the one-sample $t$-test. The formula used to compute the smoothness is that used in FSL (see http://www. fmrib.ox.ac.uk/analysis/techrep/tr00df1/tr00df1/node6.html for more information).

\section{Correlation analysis}

Correlation analysis was calculated between brain activities and the behavioral performances to support our hypothesis. We used peak beta values of the survived clusters as the index of brain activities in related brain regions. First, the correlation between precuneus activation and the switch cost (RT in con_INCON > incon_INCON, incon_CON $>$ con_CON). Second, the correlations between brain activations in superior temporal gyrus and posterior cingulate cortex and the switch cost (RT in con_INCON > incon_INCON) in easy-to-difficult switching trials.

\section{Results}

\section{Behavioral performance}

First, significant Stroop effect was observed when comparing incongruent trials to congruent tirals $[t=7.621$, $p<0.001]$, which proved that the Stroop task is valid in current study. A repeated-measures ANOVA (current trial type (CON, INCON) * previous trial type (con, incon)) indicated a significant effect of condition on response time (RT) $[F(3,29)=34.879, p=0.00]$. Post-Hoc analysis (LSD) revealed that both switching situations show longer RT than repeating situations: incon_CON $>$ con_CON $[F(1,29)=21.318, p=0.00]$, and con_INCON $>$ incon_ INCON $[F(1,29)=56.109, p=0.00]$ (Table 1). Significant difference was also found when comparing incon_CON to con_INCON $[F=4.312, p<0.05]$, but this was out of our research interest. In error rates, most participants reached a very high accuracy (Mean $=98.3 \%$ ), thus, we did not compare these results in present study.

\section{Imaging results}

\section{Difficult-to-easy (incon_CON > Con_CON)}

In congruent trials, the switching situation (incon_CON) elicited higher brain activation in left precuneus than repeating trials (con_CON)(Table 2, Figure 2a). Beta figure showed that the difference was caused by the enhanced brain activations in switching situations (incon-CON) (Figure 2b).

\section{Easy-to-difficult (con-INCON > incon-INCON)}

In incongruent trials, the switching situation (conINCON) brought high brain activations in precuneus and superior temporal gyrus (STG), bilateral middle frontal gyrus, bilateral posterior cingulate cortex (PCC), right superior frontal gyrus, and right inferior frontal gyrus (IFG) than repeating trials (Table 2; Figure 3a). Beta figures showed that all of these differences were caused by the enhanced brain activations in switching siutations (con_INCON) (Figure 3:b1, b2, b3, b4).

\section{Correlation results}

First, significant correlation was found between the brain activity in precuneus (peak Beta value) and the switch cost in con_INCON $>$ incon_INCON $(r=0.439$, $p=0.015)$, and incon_CON $>$ con_CON $(r=0.415, p=0.023)$

Table 1 Behavioral performance among different comparisons

\begin{tabular}{lllll}
\hline & $\boldsymbol{R T}$ (Mean) & SD & $\boldsymbol{F}$ & $\boldsymbol{p}$ \\
\hline con-CON & 613.61 & 130.556 & 21.3 & .000 \\
incon-CON & 715.14 & 158.333 & & \\
incon-INCON & 649.16 & 140.952 & 56.109 & .000 \\
con-INCON & 747.14 & 172.656 & & \\
\hline
\end{tabular}

The RT in different conditions is the second trial (the capital one) during the switching/repeating situation. 
Table 2 Regional brain activity changes in different comparisons

\begin{tabular}{|c|c|c|c|c|c|}
\hline$x, y, z^{a}$ & Hemisphere & Peak intensity & Number of voxels ${ }^{b}$ & Region $^{c}$ & Brodmann's area \\
\hline \multicolumn{6}{|c|}{ Incon_Con > Con_Con (Lower activated) } \\
\hline $24-6339$ & $\mathrm{R}$ & 3.817 & 34 & Precuneus & 7,31 \\
\hline \multicolumn{6}{|c|}{ Con_Incon > Incon-Incon (Higher activated) } \\
\hline$-63-18-6$ & $\mathrm{~L}$ & 7.604 & 47 & Superior_Temporal_Gyrus & 39 \\
\hline$-3-3036$ & L & 4.112 & 39 & Precuneus, Angular gyrus & 7,31 \\
\hline-39516 & $\mathrm{~L}$ & 5.367 & 170 & Middle_Frontal_Gyrus & 46 \\
\hline-331830 & $\mathrm{~L}$ & 4.992 & 89 & Middle_Frontal_Gyrus & 9 \\
\hline 333939 & $\mathrm{R}$ & 4.241 & 53 & Middle_Frontal_Gyrus & 9 \\
\hline $33-939$ & $\mathrm{R}$ & 3.992 & 35 & Posterior_Cingulate_Cortex & 31 \\
\hline $1548-15$ & $\mathrm{R}$ & 3.936 & 48 & Superior_Frontal_Gyrus & 11 \\
\hline 483318 & $\mathrm{R}$ & 5.270 & 212 & Inferior_Frontal_Gyrus & $8,9,46$ \\
\hline
\end{tabular}

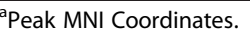

${ }^{b}$ We first identified clusters of contiguously significant voxels at an uncorrected threshold $p<0.01$, as also used for display purposes in the figures. We then tested these clusters for cluster-level FWE correction $p<0.01$ and the AlphaSim estimation indicated that clusters with 30 contiguous voxels would achieve an effective FWE threshold $p<0.01$. Voxel size $=3 * 3 * 3$.

'The brain regions were referenced to the software Xjview (http://www.alivelearn.net/xjview8) and double checked with atlas.

(Figure 2c, 3c1). Significant correlations were also found between brain activations in STG $(r=0.407, p=0.026)$ and PCC $(r=0.376, p=0.041)$ and the switch cost (RT in con_INCON $>$ incon_INCON) in easy-to-difficult switching trials (Figure 3:c2, c3).

\section{Brain activations in con_CON and incon_INCON}

To find the potential priming or facilitating effect that might hide behind the executive function, we observed the brain activations in con_CON $<$ all switching trials and incon_INCON $<$ all switching trials, separately. The logic is that if there are overlapping brain regions that activated in both conditions, and the brain regions show increase/decrease activation within repeat/switching condition. That can prove that priming effect involved/ excluded in this task. Figure 4 shows the brain regions that survived in different comparisons: There is no overlapping brain regions survived in these two conditions. In addition, previous priming studies showed that the middle temporal gyrus and the middle frontal gyrus are typically engaged in this process [33-35]. However, from the survived clusters in different comparisons, we cannot find relevant brain regions activated in this study. All these results might suggest that no priming effect exist during this process.

\section{Discussion}

More attention engaged in switching trials

Higher precuneus activations were found in both switching situations (incon_CON; con_INCON) when comparing with relevant repeating ones. The precuneus is near the superior parietal area [39] implicated in the control of
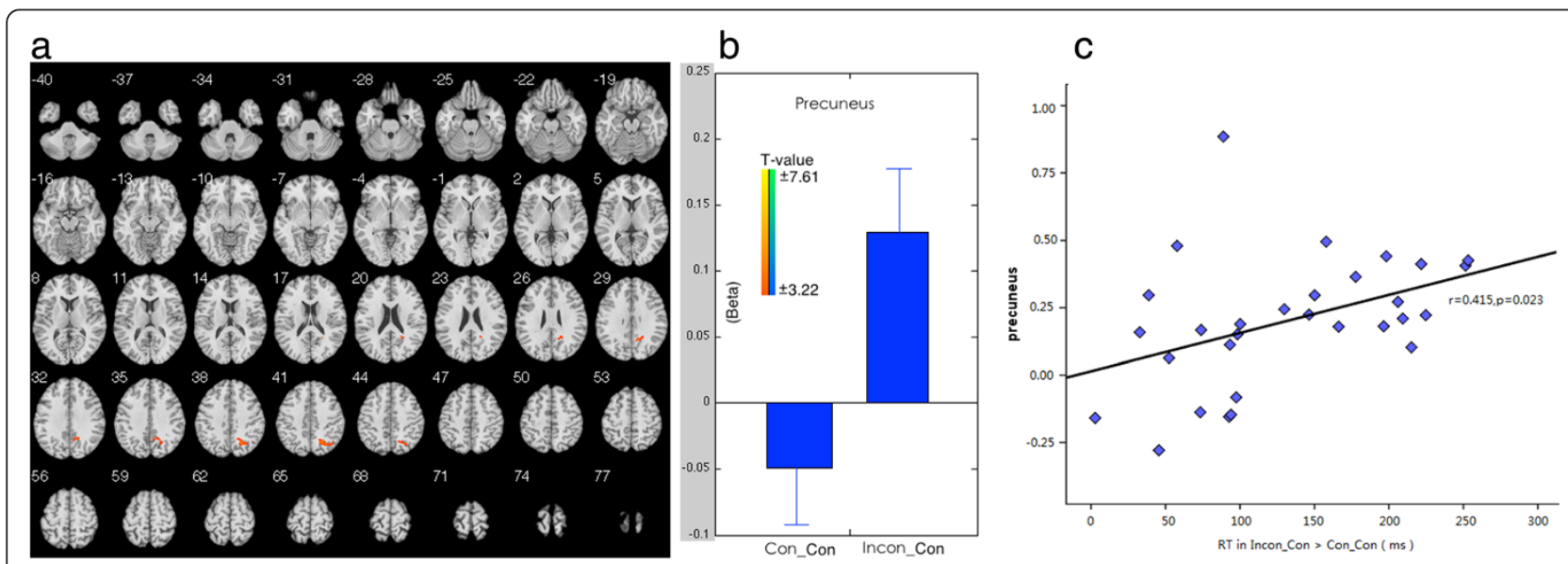

Figure 2 Imaging results in difficult-to-easy switching situation. $\mathbf{a}$, The imaging results showed that the switching condition elicited higher brain activation in right precuneus. $\mathbf{b}$, Beta figures of the survived cluster in different conditions. $\mathbf{c}$, Correlation between brain activations in precuneus and switching cost (RT in Incon_Con > Con_Con). 


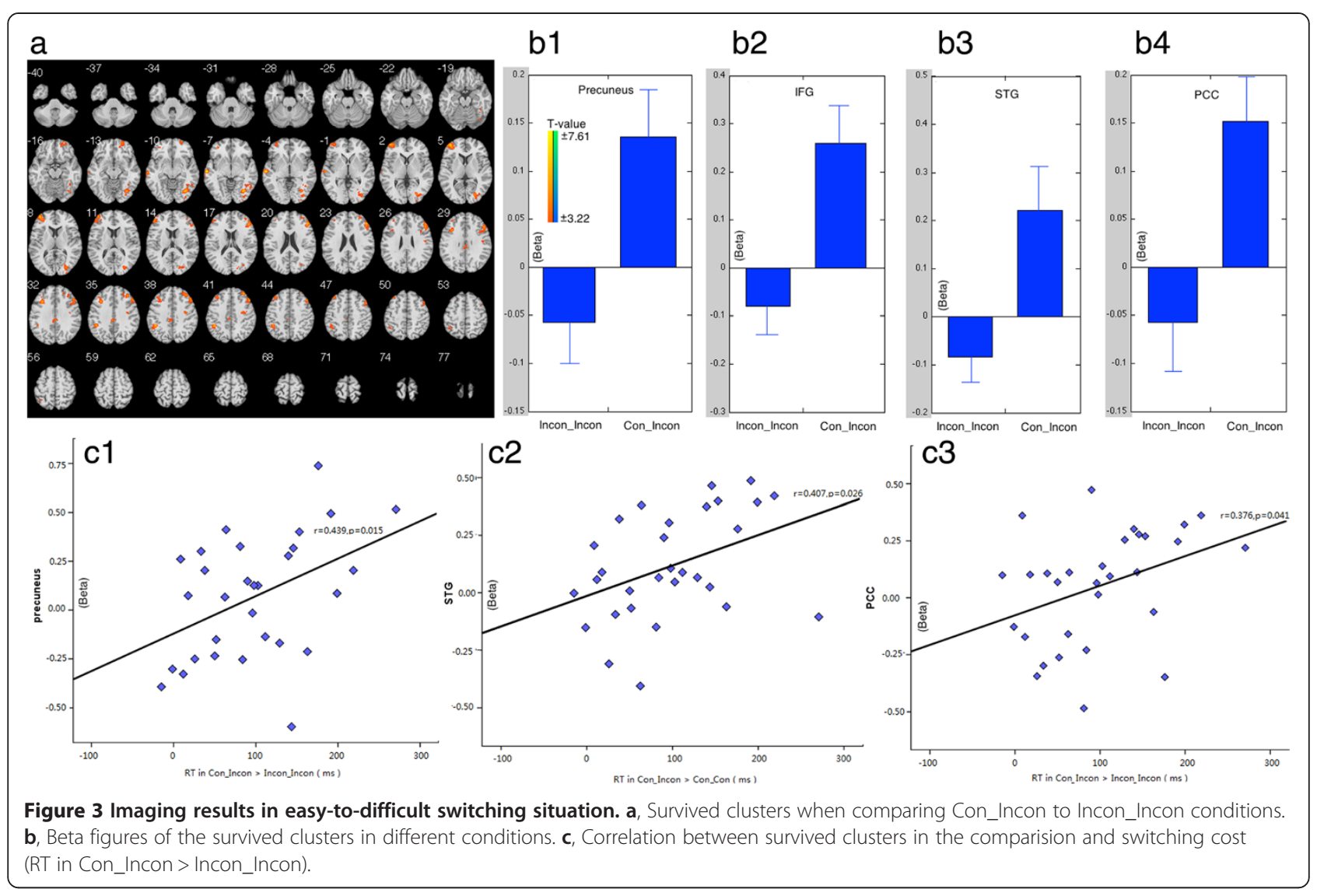

attentional switching, and switching attention between visual attributes [40]. Previous studies have found that the precuneus activities reflect increased visual attention due to more difficult task demands [41,42]. Studies on cognitive inflexibility found lower precuneus activities in major depression subjects which reflected deficits in attention control [41]. Astafiev found that the precuneus was more active in challenging tasks than in simple tasks [43]. All these results suggest that precuneus activities increase with the increase of attentional demands. In this study, the correlations between precuneus activations and the switch cost in different switching situations also support this conclusion. Take the behavioral and imaging results into consideration, we conclude that the switching conditions recruited more attention than repeating ones in this study.

\section{More executive control during switching trials}

In incongruent trials, the switching situation elicited higher brain activations in left STG, bilateral PCC, and right IFG. All of these brain regions are thought related with executive control.

The STG was found activated during task shifting $[26,44]$, which is supposed to be responsible for inhibitory control in Stroop task. The STG has been found activated when inhibitory control was applied [27,45-47]. Furthermore, studies found that cocaine-dependent patients show lower gray matter density in STG than healthy controls $[48,49]$. To make sure if the STG activations were caused by inhibitory process in this study, we performed correlation analyses between STG activations and Stroop effects. The correlations in different switching situations support the conclusion that the STG activations are related with executive function in this study.

PCC is a central node of the default mode network - a set of brain regions that show strongly correlated neural activity and reliable deactivation in activity during many cognitive tasks [50,51]. PCC serves multiple roles, including an active role in the regulation of cognition and in cognitive control [52-54]. To determine whether PCC activation is related to executive control in this study, we performed the correlation analysis between the Stroop effect and activation in PCC. The significant correlation between these two measurements also supports the hypothesis.

The right IFG has been typically implicated in inhibitive tasks [55]. The right-IFG (but not left-IFG) damage in humans crucially affects inhibition and task switching $[56,57]$. Neuroimaging studies of inhibition found bilateral IFG activation [58,59], as do studies of switching or 


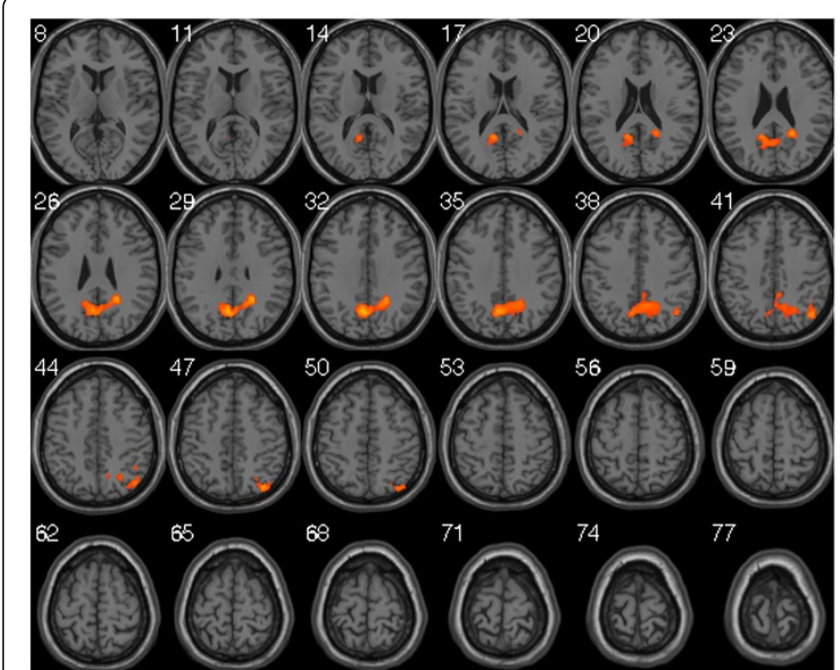

con_CON < All Switching Trials

Survived Clusters:

Left and Right Precuneus

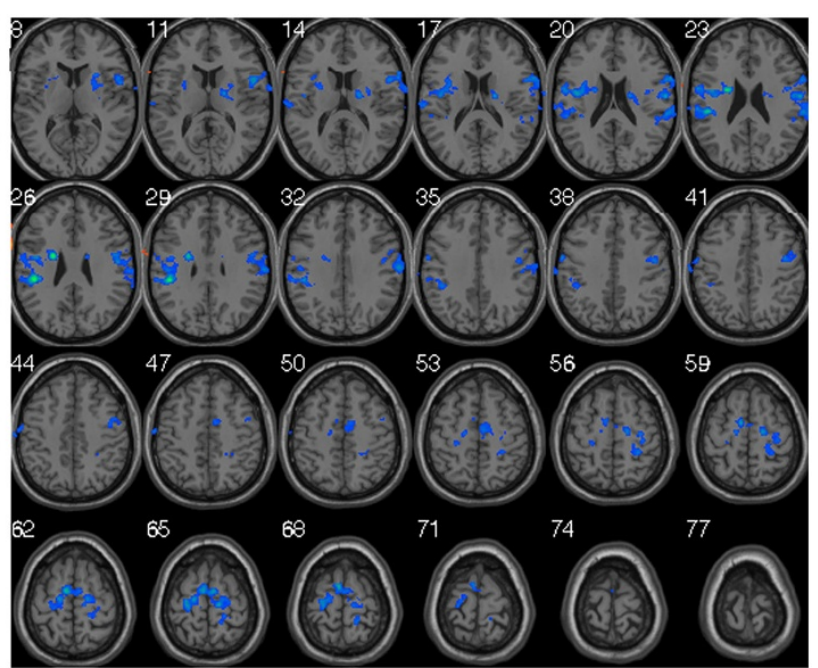

incon_INCON < All Switching Trials

Survived Clusters:

Left and Right Precuneus

Left Superior Frontal Gyrus

Right Thalamus

Left Middle Frontal Gyrus

Right Postcentral Gyrus

Figure 4 Brain activations in con_CON and incon_INCON conditions in this study.

shifting $[60,61]$. The damage of the right IFC impairs independent measures of executive control by disrupting inhibition (specifically of responses and task-sets) [55].

Take all these results into consideration, we conclude that participants engaged more executive control in the switching situation than in repeating situation.

\section{No priming or facilitating effect was found in repeating trials}

When we observing the brain activations in con_CON and incon_INCON conditions, no common brain regions were found in these two conditions, even the features of activation were totally different in different conditions (in con_CON, higher activation were found in precuneus; in incon_INCON, lower brain activation were found in some brain regions). In addition, previous priming studies showed that the middle temporal gyrus and the middle frontal gyrus are typically engaged in this process [33-35]. However, from the survived clusters in different comparisons, we did not find relevant brain regions activated in this study. Thus, from what we got, there is no priming effect observed during this process.

\section{The possible underlying mechanism}

First, priming effect was not found when observing the brain activations in con_CON and incon_INCON conditions. Which might suggest that priming effect is short of solid support in this study. Second, the switching conditions (difficult-to-easy and easy-to-difficult) recruited more attention and engaged more executive function than repeating ones, which can be indexed by the heightened brain activations in related brain regions. Third, the conflicting adaption theory believes that the switching between congruent and incongruent trials reduces the facilitating effect of consecutive repetition of congruent trials $[2,18]$. This theory paid attention to both of the facilitating effect and the endeavors engaged in executive control. Because there is no priming of facilitating effect found in this study, the current results only support part of the conflicting adaption theory.

From what we discussed above, the present study suggest that the feature that response time in switching trials are longer than in repeating trials are caused by the extra endeavors engaged in the switching processes.

\section{Limitations}

There are several limitations should be regarded here. First, since there are only 5 females and 25 males participated this study. The imbalance in gender might limit the value of the final conclusion. Second, The brain regions that activated by different switching tasks vary a lot. It is really hard to find overlapped brain regions that activated by each of these tasks and been replicated repeatedly. This study relies on inverse inference in some degrees in interpreting the brain activations during this process. Third, although there is no priming effect detected in this study, however, an alternative explanation is that the priming 
effect is fast and implicit, and it is hard to be detected by fMRI techniques. Fourth, the fast changing Stroop task might has limitation in detecting priming effect; future studies should try to explore this issue with other paradigms.

\section{Competing interests}

The authors have declared that no competing interests exist.

\section{Authors' contributions}

Conceived and designed the experiments: GD, HZ. Performed the experiments: GD, XL. Analyzed the data: GD, XL, QL. Contributed reagents/ materials/analysis tools: GD XL. Wrote the paper: GD, YH, HZ. All authors read approved the final manuscript.

\section{Funding}

This research was supported by National Science Fundation of China (31371023). The funders had no role in study design, data collection and analysis, decision to publish, or preparation of the manuscript.

\section{Author details}

'Department of Psychology, Zhejiang Normal University, 688 Yingbin Road, Jinhua, Zhejiang Province, P.R. China. ${ }^{2}$ Center for Integrative Neuroscience and Neurodynamics (CINN), School of Psychology and Clinical Language Sciences, University of Reading, Reading, UK. ${ }^{3}$ School of Life Science, University of Science and Technology of China, Hefei, Anhui Province, PR China.

Received: 31 August 2013 Accepted: 6 February 2014

Published: 13 February 2014

\section{References}

1. Botvinick M, Nystrom LE, Fissell K, Carter CS, Cohen JD: Conflict monitoring versus selection-for-action in anterior cingulate cortex. Nature 1999, 402:179-181.

2. Egner $\mathrm{T}$, Hirsch J: Cognitive control mechanisms resolve conflict through cortical amplification of task-relevant information. Nat Neurosci 2005, 8:1784-1790.

3. Kerns JG, Cohen JD, MacDonald AW 3rd, Cho RY, Stenger VA, Carter CS: Anterior cingulate conflict monitoring and adjustments in control. Science 2004, 303:1023-1026.

4. Sturmer B, Leuthold H, Soetens E, Schroter H, Sommer W: Control over location-based response activation in the Simon task: behavioral and electrophysiological evidence. J Exp Psychol Hum Percept Perform 2002, 28:1345-1363.

5. Gratton G, Coles MG, Donchin E: Optimizing the use of information: strategic control of activation of responses. J Exp Psychol Gen 1992, 121:480-506.

6. Tipper SP: The negative priming effect: inhibitory priming by ignored objects. Q J Exp Psychol A 1985, 37:571-590.

7. Liu B, Wu G, Meng X: Cross-Modal Priming Effect Based on Short-Term Experience of Ecologically Unrelated Audio-Visual Information: An Event-Related Potential Study. Neuroscience 2012, 223:21-27.

8. Milliken B, Thomson DR, Bleile K, MacLellan E, Giammarco M: Context-specific control and the Stroop negative priming effect. Q J Exp Psychol 2012, 65:1430-1448.

9. Ullsperger M, Bylsma LM, Botvinick MM: The conflict adaptation effect: it's not just priming. Cogn Affect Behav Neurosci 2005, 5:467-472.

10. Yang J, Cao Z, Xu X, Chen G: The amygdala is involved in affective priming effect for fearful faces. Brain Cogn 2012, 80:15-22.

11. Bauer E, Gebhardt H, Ruprecht C, Gallhofer B, Sammer G: Neuroimaging Evidence for Processes Underlying Repetition of Ignored Stimuli. PloS one 2012, 7:e36089.

12. Hampshire A, Owen AM: Fractionating Attentional Control Using Event-Related fMRI. Cereb Cortex 2006, 16:1679-1689.

13. Loose R, Kaufmann C, Tucha O, Auer DP, Lange KW: Neural networks of response shifting: influence of task speed and stimulus material. Brain Res 2006, 1090:146-155

14. Monsell S: Task switching. Trends Cogn Sci 2003, 7:134-140.
15. Logan GD, Gordon RD: Executive control of visual attention in dual-task situations. Psychol Rev 2001, 108:393-434

16. Witt ST, Stevens MC: fMRI task parameters influence hemodynamic activity in regions implicated in mental set switching. Neurolmage 2013, 65:139-151.

17. Botvinick MM, Braver TS, Barch DM, Carter CS, Cohen JD: Conflict monitoring and cognitive control. Psychol Rev 2001, 108:624-652.

18. Egner T: Congruency sequence effects and cognitive control. Cogn Affect Behav Neurosci 2007, 7:380-390

19. Botvinick MM, Cohen JD, Carter CS: Conflict monitoring and anterior cingulate cortex: an update. Trends Cogn Sci 2004, 8:539-546.

20. Carter CS, van Veen V: Anterior cingulate cortex and conflict detection: an update of theory and data. Cogn Affect Behav Neurosci 2007, 7:367-379.

21. Clayson PE, Larson MJ: Conflict adaptation and sequential trial effects: support for the conflict monitoring theory. Neuropsychologia 2011, 49:1953-1961.

22. Charles-Sire V, Gueguen N, Meineri S, Martin A, Bullock A: The effect of priming with a love concept on blood donation promise. Transfus Apher Sci 2013. (in press): Doi:j.transci.2013.10.009.

23. Moritz S, Woodward TS, Küppers D, Lausen A, Schickel M: Increased automatic spreading of activation in thought-disordered schizophrenic patients. Schizophr Res 2003, 59:181-186.

24. Spitzer M, Braun U, Hermle L, Maier S: Associative semantic network dysfunction in thought-disordered schizophrenic patients: Direct evidence from indirect semantic priming. Biol Psychiatry 1993, 34:864-877.

25. Spitzer M, Weisker I, Winter M, Maier S, Hermle L, Maher BA: Semantic and phonological priming in schizophrenia. J Abnorm Psychol 1994, 103:485-494.

26. Wager TD, Jonides J, Reading S: Neuroimaging studies of shifting attention: a meta-analysis. Neurolmage 2004, 22:1679-1693.

27. Braver TS, Barch DM, Gray JR, Molfese DL, Snyder A: Anterior Cingulate Cortex and Response Conflict: Effects of Frequency, Inhibition and Errors. Cereb Cortex 2001, 11:825-836.

28. Derrfuss J, Brass M, Yves von Cramon D: Cognitive control in the posterior frontolateral cortex: evidence from common activations in task coordination, interference control, and working memory. Neurolmage 2004, 23:604-612.

29. Rubia K, Smith AB, Woolley J, Nosarti C, Heyman I, Taylor E, Brammer M: Progressive increase of frontostriatal brain activation from childhood to adulthood during event-related tasks of cognitive control. Hum Brain Mapp 2006, 27:973-993.

30. Smith AB, Taylor E, Brammer M, Rubia K: Neural correlates of switching set as measured in fast, event-related functional magnetic resonance imaging. Hum Brain Mapp 2004, 21:247-256.

31. Casey BJ, Thomas KM, Davidson MC, Kunz K, Franzen PL: Dissociating Striatal and Hippocampal Function Developmentally with a Stimulus-Response Compatibility Task. J Neurosci 2002, 22:8647-8652.

32. Luna B, Thulborn KR, Munoz DP, Merriam EP, Garver KE, Minshew NJ, Keshavan MS, Genovese CR, Eddy WF, Sweeney JA: Maturation of Widely Distributed Brain Function Subserves Cognitive Development. Neurolmage 2001, 13:786-793.

33. Kotz SA, Cappa SF, von Cramon DY, Friederici AD: Modulation of the lexical-semantic network by auditory semantic priming: an event-related functional MRI study. Neurolmage 2002, 17:1761-1772.

34. Tivarus ME, Ibinson JW, Hillier A, Schmalbrock P, Beversdorf DQ: An fMRI study of semantic priming: modulation of brain activity by varying semantic distances. Cogn Behav Neurol 2006, 19:194-201.

35. Laufer I, Negishi M, Lacadie CM, Papademetris X, Constable RT: Dissociation between the Activity of the Right Middle Frontal Gyrus and the Middle Temporal Gyrus in Processing Semantic Priming. PloS one 2011, 6:e22368.

36. Lecrubier $Y$, Sheehan DV, Weiller E, Amorim P, Bonora I, Harnett Sheehan K, Janavs J, Dunbar GC: The Mini International Neuropsychiatric Interview (MINI). A short diagnostic structured interview: reliability and validity according to the CIDI. Eur Psychiatry 1997, 12:224-231.

37. Beck AT, Ward CH, Mendelson M, Mock J, Erbaugh J: An Inventory for Measuring Depression. Arch Gen Psychiatry 1961, 4:561-571.

38. Dong G, Shen Y, Huang J, Du X: Impaired error-monitoring function in people with internet addiction disorder: an event-related FMRI study. Eur Addict Res 2013, 19:269-275.

39. Gurd JM, Amunts K, Weiss PH, Zafiris O, Zilles K, Marshall JC, Fink GR: Posterior parietal cortex is implicated in continuous switching between verbal fluency tasks: an fMRI study with clinical implications. Brain 2002, 125:1024-1038. 
40. Le TH, Pardo JV, Hu X: 4 T-fMRI Study of Nonspatial Shifting of Selective Attention: Cerebellar and Parietal Contributions. J Neurophysiol 1998, 79:1535-1548.

41. Remijnse PL, van den Heuvel OA, Nielen MMA, Vriend C, Hendriks G-J, Hoogendijk WJG, Uylings HBM, Veltman DJ: Cognitive Inflexibility in Obsessive-Compulsive Disorder and Major Depression Is Associated with Distinct Neural Correlates. PloS one 2013, 8:e59600.

42. Barber AD, Carter CS: Cognitive Control Involved in Overcoming Prepotent Response Tendencies and Switching Between Tasks. Cereb Cortex 2005, 15:899-912.

43. Astafiev SV, Shulman GL, Stanley CM, Snyder AZ, Essen DCV, Corbetta M: Functional Organization of Human Intraparietal and Frontal Cortex for Attending, Looking, and Pointing. J Neurosci 2003, 23:4689-4699.

44. Buchsbaum BR, Greer S, Chang W-L, Berman KF: Meta-analysis of neuroimaging studies of the Wisconsin Card-Sorting task and component processes. Hum Brain Mapp 2005, 25:35-45.

45. Garavan H, Ross TJ, Stein EA: Right hemispheric dominance of inhibitory control: An event-related functional MRI study. PNAS 1999, 96:8301-8306

46. Kiehl KA, Liddle PF: An event-related functional magnetic resonance imaging study of an auditory oddball task in schizophrenia. Schizophr Res 2001, 48:159-171.

47. Garavan H, Ross TJ, Murphy K, Roche RAP, Stein EA: Dissociable executive functions in the dynamic control of behavior: inhibition, error detection, and correction. Neurolmage 2002, 17:1820-1829.

48. Franklin TR, Acton PD, Maldjian JA, Gray JD, Croft JR, Dackis CA, O'Brien CP, Childress AR: Decreased gray matter concentration in the insular, orbitofrontal, cingulate, and temporal cortices of cocaine patients. Biol Psychiatry 2002, 51:134-142.

49. Sim ME, Lyoo IK, Streeter CC, Covell J, Sarid-Segal O, Ciraulo DA, Kim MJ, Kaufman MJ, Yurgelun-Todd DA, Renshaw PF: Cerebellar Gray Matter Volume Correlates with Duration of Cocaine Use in Cocaine-Dependent Subjects. Neuropsychopharmacology 2007, 32:2229-2237.

50. Raichle ME, MacLeod AM, Snyder AZ, Powers WJ, Gusnard DA, Shulman GL: A default mode of brain function. Proc Natl Acad Sci U S A 2001, 98:676-682.

51. Raichle ME, Snyder AZ: A default mode of brain function: a brief history of an evolving idea. Neurolmage 2007, 37:1083-1090. discussion 1097-1089.

52. Hampson M, Driesen NR, Skudlarski P, Gore JC, Constable RT: Brain connectivity related to working memory performance. J Neurosci 2006, 26:13338-13343.

53. Pearson JM, Heilbronner SR, Barack DL, Hayden BY, Platt ML: Posterior cingulate cortex: adapting behavior to a changing world. Trends Cogn Sci 2011, 15:143-151.

54. Leech R, Kamourieh S, Beckmann CF, Sharp DJ: Fractionating the default mode network: distinct contributions of the ventral and dorsal posterior cingulate cortex to cognitive control. J Neurosci 2011, 31:3217-3224.

55. Aron AR, Robbins TW, Poldrack RA: Inhibition and the right inferior frontal cortex. Trends Cogn Sci 2004, 8:170-177.

56. Aron AR, Fletcher PC, Bullmore ET, Sahakian BJ, Robbins TW: Stop-signal inhibition disrupted by damage to right inferior frontal gyrus in humans. Nature Neurosci 2003, 6:115-116.

57. Aron AR, Monsell S, Sahakian BJ, Robbins TW: A componential analysis of task-switching deficits associated with lesions of left and right frontal cortex. Brain 2004, 127:1561-1573.

58. Bunge SA, Dudukovic NM, Thomason ME, Vaidya CJ, Gabrieli JD: Immature frontal lobe contributions to cognitive control in children: evidence from fMRI. Neuron 2002, 33:301-311.

59. Konishi S, Nakajima K, Uchida I, Kikyo H, Kameyama M, Miyashita Y: Common inhibitory mechanism in human inferior prefrontal cortex revealed by event-related functional MRI. Brain 1999, 122:981-991.
60. Nakahara K, Hayashi T, Konishi S, Miyashita Y: Functional MRI of macaque monkeys performing a cognitive set-shifting task. Science 2002, 295:1532-1536.

61. Monchi O, Petrides M, Petre V, Worsley K, Dagher A: Wisconsin Card Sorting revisited: distinct neural circuits participating in different stages of the task identified by event-related functional magnetic resonance imaging. J Neurosci 2001, 21:7733-7741.

doi:10.1186/1744-9081-10-4

Cite this article as: Dong et al:: Why the processing of repeated targets are better than that of no repetition: evidence from easy-to-difficult and difficult-to-easy switching situations. Behavioral and Brain Functions 2014 10:4.

\section{Submit your next manuscript to BioMed Central and take full advantage of:}

- Convenient online submission

- Thorough peer review

- No space constraints or color figure charges

- Immediate publication on acceptance

- Inclusion in PubMed, CAS, Scopus and Google Scholar

- Research which is freely available for redistribution 